\title{
Assessment of posttraumatic stress disorder-related functional impairment:
} A review

\author{
Paola Rodriguez, PhD; Darren W. Holowka, PhD; Brian P. Marx, PhD* \\ Department of Veterans Affairs (VA) National Center for Posttraumatic Stress Disorder at VA Boston Healthcare System, \\ Boston, MA; Boston University School of Medicine, Boston, MA
}

\begin{abstract}
In 2010, the Department of Veterans Affairs (VA) and Department of Defense (DOD) jointly published the revised VA/DOD Clinical Practice Guideline for Management of Posttraumatic Stress. The Clinical Practice Guideline (CPG) provides evidence-based recommendations for diagnosing and treating a spectrum of stress-related disorders. Included in the CPG were recommendations for assessing posttraumatic stress disorder (PTSD) and other stress disorder-related functional impairment. This article complements those CPG recommendations by providing information that may further guide clinicians in the assessment of functional impairment related to PTSD and other stress-related disorders. We briefly review some of the empirical literature on the association between PTSD and functional impairment and some of the more frequently used methods and measures for assessing functional impairment and introduce a new measure currently being developed by our group. We suggest that information obtained via patient self-report and/or clinician rating be supplemented whenever possible with collateral data from friends, family members, coworkers, or supervisors to provide a complete picture of current and premorbid functional status. Finally, we explore several important issues that we encourage clinicians to keep in mind when assessing functional impairment among Veterans and Active Duty servicemembers.
\end{abstract}

Clinical Trial Registration: ClinicalTrials.gov; PT074941, "Development and validation of a PTSD-related functional impairment scale;” http://www.clinicaltrials.gov.

Key words: clinical practice guideline, Department of Defense, Department of Veterans Affairs, education, family, functional impairment, intimate relationships, occupational functioning, posttraumatic stress disorder, social functioning.

\section{INTRODUCTION}

Research has consistently shown posttraumatic stress disorder (PTSD) to be associated with impairments in functioning across a number of psychosocial domains [1]. Specifically, PTSD is associated with impairments in occupational and academic functioning [2-6], marital and family functioning [5,7-8], parenting [9-10], and friendships and socializing [11]. Additional studies have shown associations between PTSD and objective indicators of quality of life (QOL) such as homelessness and unemployment [12-13]. Such impairments are common among

\footnotetext{
Abbreviations: ASD = acute stress disorder; CAPS = ClinicianAdministered PTSD Scale; COSR = combat and operational stress reaction; $\mathrm{CPG}=$ clinical practice guideline; $\mathrm{DOD}=$ Department of Defense; DSM-IV-TR = Diagnostic and Statistical Manual of Mental Disorders, Fourth Edition, Text Revision; GAF = Global Assessment of Functioning; IOM = Institute of Medicine; IPF = Inventory of Psychosocial Functioning; LIFE = Longitudinal Interval Follow-Up Evaluation; $\mathrm{M}=$ mean impairment score; OIF/OEF = Operation Iraqi Freedom/Operation Enduring Freedom; PTSD = posttraumatic stress disorder; $\mathrm{QOL}=$ quality of life; SD = standard deviation; VA = Department of Veterans Affairs; WHO = World Health Organization; WHODAS-II = WHO Disability Assessment Schedule II.

*Address all correspondence to Brian P. Marx, PhD; VA National Center for Posttraumatic Stress Disorder at VA Boston Healthcare System, 150 S Huntington Ave, 116B-4, Boston, MA 02130; 857-364-6071; fax: 857-364-4501; Email: Brian.Marx@va.gov http://dx.doi.org/10.1682/JRRD.2011.09.0162
} 
populations at high risk for PTSD, such as military personnel deployed to combat [3,5-6,8-14]. Research suggests that these impairments are currently affecting many Veterans of the wars in Iraq and Afghanistan (Operations Iraqi Freedom and Enduring Freedom) and are therefore important to identify and treat [15].

In 2010, the Department of Veterans Affairs (VA) and the Department of Defense (DOD) jointly published the revised VA/DOD Clinical Practice Guideline for Management of Posttraumatic Stress [16]. This clinical practice guideline (CPG) provides evidence-based recommendations to clinicians for diagnosing and treating a spectrum of stress-related disorders including combat and operational stress reaction (COSR), acute stress reaction, acute stress disorder (ASD), acute PTSD, and chronic PTSD among servicemembers and Veterans.

The VA/DOD CPG recommends a comprehensive assessment of all relevant domains of functioning. It stresses the importance of a thorough assessment of functional impairment for several reasons: (1) to identify individuals who may be at risk for endangering themselves or others during or after deployment as well as after military discharge, (2) to promote accurate diagnosis, (3) to guide treatment planning by clarifying the domains in which the individual is experiencing impairment, and (4) to monitor changes in functioning during and after treatment.

This article is meant to complement the CPG recommendations for assessing stress disorder-related functional impairment and will provide information that may further guide clinicians in their assessment efforts. Although the VA/DOD CPG addresses several stress-related disorders, this article will focus mainly on the relation between PTSD and psychosocial functioning because the vast majority of prior research has examined this association. The information provided is based on these empirical findings from the extant literature as well as recent findings from an ongoing study of functional impairment among male and female Veterans. Specifically, we begin our article with a review of some of the recent empirical literature on the association between PTSD and impaired functioning across various psychosocial domains. We then provide specific recommendations on how to perform a comprehensive multimethod assessment of functional impairment and introduce a promising new assessment instrument. The article concludes with insights into several important issues related to assessing functional impairment that we encourage all clinicians to keep in mind when assessing functional impairment among Veterans and Active Duty servicemembers.

\section{METHODS}

We searched the U.S. National Library of Medicine's PubMed, PsycINFO, and PsycARTICLES databases for articles related to PTSD and functioning. We identified studies by searching the databases for references with the phrases "posttraumatic stress disorder" or "PTSD" $(n=$ 10,109 English-language articles) or "functioning" in the title or abstract ( $n=83$ ). We reviewed the abstracts for the resulting articles to identify those relevant to our topic, and we also reviewed the references for the most relevant articles to identify additional studies of interest. Because we were unable to provide an exhaustive literature review in this article, we emphasized studies published since 2008 but also included a few earlier articles that were of particular relevance.

To identify articles related to impairment in specific domains associated with PTSD, we searched the PsycINFO and PsycARTICLES databases for articles with the search terms "posttraumatic" or "PTSD" in the major subject heading and "marriage," "parenting," "social functioning," "work," "education,” "school," "finances," and "homelessness" in the subjects fields. We reviewed the results to determine whether the study addressed functional impairment related to PTSD. After identifying relevant screening measures, we performed additional searches to locate articles about the measures in question, including original validation studies.

This article also presents data collected through a grant awarded to Brian Marx, $\mathrm{PhD}$, by the Department of Defense with the goal of designing and validating a new measure of functional impairment related to PTSD. This project was observational and cross-sectional. Phase $1(n=53)$ involved the use of focus groups to obtain information about the domains related to impairment among Veterans with PTSD. Phase 2's test development sample and hypothesis testing $(n=285)$ involved the use of clinical interviews and selfreport questionnaires administered to male and female Veterans with representation from the Vietnam, Persian Gulf, and Operation Iraqi Freedom/Operation Enduring Freedom (OIF/OEF) conflicts. For Phase 3, involving test validation and hypothesis testing, a sample of 1,800 Active Duty personnel and 300 Veterans from the Vietnam, Persian Gulf, and OIF/OEF conflicts were recruited. 


\section{RESULTS}

\section{Empirical Findings on Relation Between PTSD and Functional Impairment}

Prior research has found strong and reliable associations between PTSD and functional impairment. Studies usually show these associations to be characterized by medium to large effect sizes [e.g., 9,15,17]. A comprehensive review of the literature on the association between PTSD and psychosocial functioning is beyond the scope of this article. For thorough reviews, please see Holowka and Marx [1], Schnurr et al. [18], Sayer et al. [19], and Norman et al. [20]. We briefly review some of the more recently published literature in this area as well as some of the findings from our current work. Specifically, we discuss findings describing the associations between PTSD and difficulties in intimate relationships, friendships and socializing, parenting, work and academic performance, and financial problems and homelessness.

\section{Intimate Relationships}

Recent research has found that the symptoms of PTSD frequently result in deleterious consequences for intimate relationships. Combat Veterans with PTSD have been reported twice as likely as non-PTSD Veterans to be divorced and three times as likely as those without PTSD to experience multiple divorces [21]. Studies have found that PTSD avoidance/numbing symptoms (e.g., anhedonia, emotional detachment from others, avoidance of traumarelated thoughts and feelings) are strongly associated with intimate relationship problems among Veterans [22-24]. In the context of intimate relationships, avoidance may initiate a cycle in which withdrawal and reluctance to discuss the past may strengthen feelings of uncertainty and loneliness. This, in turn, reinforces the partner's apprehension, which leads to further withdrawal on the Veteran or servicemember's part [23]. Monson et al. also theorized that difficulties with effective trauma disclosure and poor conflict resolution may lead to poor communication, which in turn exacerbates relationship problems [23]. Consistent with these hypotheses, Veterans in our ongoing study ${ }^{*}$ commonly reported that PTSD avoidance and numbing

\footnotetext{
*Marx BP, Schnurr P, Rodriguez P, Holowka DW, Lunney C, Weathers F, Sloan D, Keane TM. Development and validation of a scale to assess functional impairment among active duty service members and veterans. 25th Annual Meeting of the International Society for Traumatic Stress Studies; 2009 Nov 5-7; Atlanta, GA.
}

symptoms were related to an increasing reluctance to participate in previously enjoyable activities with their partners. Many of these Veterans described a new preference for quiet, solitary activities, such as watching television or fishing, as well as a preference for activities they could perform without leaving the house.

Hyperarousal symptoms of PTSD have also been associated with greater intimate relationship difficulties. In particular, studies have found that increased anger, irritability, and aggression are related to problems in intimate relationships [17,25-26]. PTSD-related hyperarousal symptoms may also contribute to challenges that Veterans and their partners face when they engage in activities in public places. For example, PTSD-related hypervigilence may lead to Veterans avoiding crowds or prematurely or abruptly leaving social events when their partners are not ready to leave, sitting in certain places (e.g., near an exit or with their backs to the wall) when dining or in public, having problems regulating affect in public, and creating discomfort for their partners [27-28]. PTSD-related hyperarousal may also lead to problems related to driving; partners of Veterans with PTSD often complain of "road rage" and difficulty tolerating aggressive or risky driving, which can lead to frequent arguments [23,24].

It has been hypothesized that combat Veterans with PTSD may experience trouble processing threatening social stimuli because these events may activate "survival mode” reactions characterized by increased physiological arousal, hostile appraisals, and defensive behavior, which may have been adaptive in life-threatening contexts (e.g., combat), but are no longer adaptive and can lead to problems in their current contexts [17].

It is also important to keep in mind that relationships are cocreated and a spouse/partner may also be experiencing his or her own difficulties, which can contribute equally or more so to discord in the relationship. Finally, it is also worth noting that, in addition to acting as a causal factor, PTSD symptoms can worsen or intensify existing problems.

\section{Friendships and Socializing}

Data from our ongoing study show that avoidance and numbing symptoms also impair friendships. Specifically, we found that PTSD symptoms were associated with difficulties in sharing thoughts or feelings, being emotionally supportive, and settling arguments or disagreements with friends. Our data have also shown that, although PTSDrelated hypervigilance interfered with meeting new people, 
a combination of irritability, feelings of detachment/ estrangement, and hypervigilance were all related to impairment in friendships and socializing.

\section{Parenting}

Other recent studies have noted an association between PTSD and parenting difficulties [9-10,29]. Gewirtz et al. found that among male Vietnam Veterans PTSD symptoms were associated with decreased parenting satisfaction, impaired attachment with children, child behavior problems, and family violence [30]. PTSD symptoms were also associated with less effective parenting (e.g., inconsistent discipline and poor supervision). In trying to explain how PTSD symptoms result in parenting difficulties, investigators have suggested that avoidance and numbing symptoms may produce impaired relationships through emotional and physical detachment, lack of interest, and reduced monitoring and involvement with children [31], while hyperarousal symptoms may be associated with volatile or emotionally dysregulated parent-child interactions, especially in stressful situations [30].

Clinicians and researchers have identified the emotional numbing and hyperarousal components of PTSD as particularly disruptive of the Veteran's family life [28]. Galovski and Lyons suggested that fear and guilt over violent impulses acted on during combat situations and in the home, and current attempts to control these impulses, may lead the Veteran to avoid certain roles and activities that, in turn, affect the Veteran's overall ability to perform familial responsibilities and may further estrange them from their loved ones [28]. Such withdrawal and avoidance may create other problems in the home because the other parent or partner may struggle with the increased responsibility and burden placed on him or her [27-28].

\section{Work and Academic Performance}

Recent studies have confirmed the results of earlier studies demonstrating that PTSD symptoms can adversely affect work and academic performance, as well as the interactions with supervisors and peers in these domains [2,3234]. Rona et al. found that, among a sample of U.K. military personnel, PTSD-related avoidance and numbing symptoms, followed by hyperarousal symptoms, were most strongly associated with poor performance at work, (e.g., less time on task, less accomplished, difficulty performing duties) [5]. Sleep disturbances have been shown to adversely affect work and academic performance, as evi- denced by increased absenteeism and reduced productivity [35-36]. Fernandez-Mendoza et al. showed that sleep disturbances were associated with worse neuropsychological performance on tasks involving processing speed, executive control of attention, and visual memory, all of which can affect work and academic performance [37].

Other studies, including Heir et al. [34] and the ongoing study by Marx et al., have confirmed that greater PTSD symptom severity is associated with an increased number of days absent from work. Other investigators have found that exposure to trauma among a sample of Active Duty military personnel predicted increases in PTSD symptoms, as well as job burnout, job stress, work-family conflict, and job dissatisfaction [38]. Research with women has also found negative associations between a history of interpersonal violence and job satisfaction and productivity [32]. Bolton et al. found that, once again, PTSD-related symptoms of avoidance, numbing, and hypervigilence can deleteriously affect academic performance [2], and research with adolescents has found associations between PTSD and school truancy and suspensions [39]. Adolescents with PTSD show slower processing of incoming information and difficulties in concentration and decision-making, which can have negative consequences for functioning in school [39].

\section{Financial Problems and Homelessness}

Parto et al. examined the prevalence of PTSD among urban residents and found that men and women living below the poverty level were more likely to screen positive for PTSD compared with those living above the poverty level [40]. They also found that, among participants at all income levels, people aged 30 to 47 years were more likely to report symptoms of PTSD than those aged 47 to 64 years. Women were more likely than men to screen positive for PTSD; white participants were more likely than African-American participants to endorse PTSD. Lastly, results showed that white women living below the poverty level were most likely to report PTSD symptoms [40].

An estimated 2.3 to 3.5 million people experience homelessness in the United States in a given year, and an estimated 26 percent of homeless adults are Veterans [41]. Women who have served in the military are three to four times more likely to become homeless than nonveteran women, though the reasons for this are unclear [41]. Results from a recent study of homelessness showed that, in general, male Veterans report homelessness because of job loss, discharge from an institution, mental health problems, and 
alcohol or drug problems. In contrast, female Veterans usually report homelessness because of eviction, interpersonal conflict, and the loss of someone they depended on financially (either through disruption of that relationship or because of illness or death) [42]. Recent research focusing specifically on Veterans has shown that important risk factors for homelessness include extreme poverty, a postmilitary psychiatric disorder, and social isolation. Additional studies with homeless Veterans have found associations between PTSD and homelessness and financial loss [41,43]. Homeless female Veterans were more likely to screen positive for PTSD than nonhomeless female Veterans. These women were also more likely to have experienced military sexual trauma, to be unemployed, and to be disabled [41]. Importantly, Galea et al. have shown that there may be reciprocal associations between financial loss and PTSD [43]. Specifically, they showed that, in the aftermath of Hurricane Katrina, financial loss predicted PTSD diagnostic status 2 years posttrauma.

\section{Assessment of Functional Impairment}

We recommend that the assessment of functional impairment be accomplished using both clinical interviews and self-report instruments that assess functioning more broadly in addition to specific domains. Although researchers have successfully developed a number of valuable methods that can reliably and validly assess functional impairment, the information derived from these methods may be affected by therapist-client rapport, memory biases, response biases, cultural biases, and clinical orientation. Further, reliance on a single assessment methodology or instrument may lead to an inaccurate understanding of the forms and degrees of functional impairment. As a result of these limitations, we recommend the use of multiple methods and measures. Such multimethod assessment takes advantage of each measure's relative strengths, overcoming the psychometric limitations of any single instrument and maximizing correct diagnostic decisions. We suggest that information obtained via patient self-report or clinician rating be supplemented with data from friends, family members, coworkers, supervisors, or teachers to provide a complete picture of current and premorbid functional status. Although these corroborating reports are also subjective, when combined with other data, they may strengthen the resulting conclusions.

Consistent with the CPG recommendation to monitor changes in functioning over time, past research has shown that the nature of the relation between psychiatric symptomatology and functioning may vary [13,44-45]. Changes in functioning over time have important implications for both the diagnosis and treatment of individuals with PTSD and other stress-related disorders. With respect to diagnosis, the time point at which functional impairment is noted will determine which diagnosis is allowed by the current classification scheme. Specifically, if dysfunction is noted within the first 30 days of exposure to a traumatic event (along with the other requisite symptoms), then the clinician would consider COSR or ASD as viable diagnoses. If dysfunction and associated symptoms are present for at least a month but less than 3 months, then the clinician should consider acute PTSD as a diagnosis. If dysfunction and associated symptoms are present for 3 months or longer, then clinicians should consider diagnosing the individual with chronic PTSD.

With respect to treatment, the practice of assessing functioning over time is beneficial to see how changes in QOL and functioning may or may not correlate with therapy-related changes in symptomatology. Such assessment also provides clinicians with information needed to make modifications to treatment intensity (frequency and duration), goals, mode (individual, group, couple, family), and specific strategies and techniques [46] for the purpose of meeting the changing needs of their patients. In some cases, PTSD symptoms may not change or decrease, but the person may learn new skills in therapy to cope more effectively with his or her symptoms. In these instances, a designated informant may observe improvements in functioning or QOL (an individual's subjective appraisal of his or her physical, mental, and social well-being) [18] before the Veteran. Some commonly used QOL measures include the World Health Organization (WHO) QOL Assessment [47], the QOL Inventory [48], and the Satisfaction with Life Scale [49]. For more detailed description of these measures, please see the Table.

\section{Interviews}

It is beyond the scope of this article to review all available interview measures. We review some of the more commonly used ones here. Specific questions within various clinician-administered diagnostic interviews assess the extent to which an individual is experiencing overall functional impairment related to PTSD and other stress-related disorders. For example, the Clinician-Administered PTSD Scale (CAPS) [65] and the Structured Clinical Interview 
JRRD, Volume 49, Number 5, 2012

Table.

Measures of functional impairment and quality of life.

\begin{tabular}{|c|c|c|c|}
\hline Measure & Domains Assessed & Description & Items \\
\hline $\begin{array}{l}\text { World Health Organization } \\
\text { Disability Assessment } \\
\text { Schedule-II (WHODAS-II) } \\
\text { [50] }\end{array}$ & $\begin{array}{l}\text { 1. Understanding and communicating } \\
\text { 2. Mobility } \\
\text { 3. Self-care } \\
\text { 4. Interpersonal } \\
\text { 5. Work and household } \\
\text { 6. Participation in society }\end{array}$ & $\begin{array}{l}\text { Revised version of WHODAS (World Health Organization, 1988), } \\
\text { WHODAS-II is measure of impairment because of military or health- } \\
\text { related problems experienced in past } 30 \text { days. It provides profile of } \\
\text { functioning across } 6 \text { activity domains, as well as general disability } \\
\text { score. It can be administered as self-report questionnaire [48] or in } \\
\text { interview form [55]. Available to those who complete and submit user } \\
\text { agreement form. }\end{array}$ & 36 \\
\hline $\begin{array}{l}\text { Medical Outcomes Study } \\
\text { Short Form (SF-36) [51] }\end{array}$ & $\begin{array}{l}\text { 1. Physical functioning } \\
\text { 2. Role physical } \\
\text { 3. Bodily pain } \\
\text { 4. General health } \\
\text { 5. Vitality } \\
\text { 6. Social functioning } \\
\text { 7. Role emotional } \\
\text { 8. Mental health } \\
\text { 9. Health change }\end{array}$ & $\begin{array}{l}\text { Generic, widely used measure of health status. } 8 \text { domains included } \\
\text { in SF-36 were selected from } 40 \text { used in Medical Outcomes Study } \\
\text { [52]. Short form is also available (SF-12). Available to those who } \\
\text { complete and submit License Application Form. }\end{array}$ & 36 \\
\hline $\begin{array}{l}\text { Sheehan Disability Scale } \\
\text { [53] }\end{array}$ & $\begin{array}{l}\text { 1. Work/school } \\
\text { 2. Social } \\
\text { 3. Family }\end{array}$ & $\begin{array}{l}\text { Respondent rates difficulties due to symptoms in each of } 3 \text { domains } \\
\text { on } 10 \text {-point scale with verbal anchors. Author holds copyright to } \\
\text { scale; permission to use may be obtained by contacting author. }\end{array}$ & 3 \\
\hline $\begin{array}{l}\text { Sheehan Work Disability } \\
\text { Scale (SWDS) }\end{array}$ & $\begin{array}{l}\text { 1. Physical work } \\
\text { 2. Mental work (thinking, planning, using your } \\
\text { brain) } \\
\text { 3. Work closely and effectively with others }\end{array}$ & $\begin{array}{l}\text { Respondent rates difficulties in occupational functioning due to his or } \\
\text { her symptoms on } 10 \text {-point scale with anchors. Author holds copyright } \\
\text { to scale; permission to use may be obtained by contacting author. }\end{array}$ & 3 \\
\hline $\begin{array}{l}\text { Sheehan Disability Scale-W } \\
(\mathrm{SDS}-\mathrm{W})^{\dagger}\end{array}$ & $\begin{array}{l}\text { 1. Work/school } \\
\text { 2. Social life } \\
\text { 3. Family life/home responsibilities } \\
\text { 4. Balance between personal life and career }\end{array}$ & $\begin{array}{l}\text { Respondent rates extent to which he or she experiences problems in } \\
\text { each of } 4 \text { domains due to symptoms on } 10 \text {-point visual analog scale. } \\
\text { Author holds copyright to scale; permission to use may be obtained } \\
\text { by contacting author. }\end{array}$ & 4 \\
\hline $\begin{array}{l}\text { Health and Work Perfor- } \\
\text { mance Questionnaire-Short } \\
\text { Form (HPQ) [54] }\end{array}$ & $\begin{array}{l}\text { 1. Absenteeism } \\
\text { 2. Presenteeism }\end{array}$ & $\begin{array}{l}\text { Self-report measure that assesses work-related consequences of ill- } \\
\text { ness, including absenteeism, presenteeism, and workplace accidents. } \\
\text { Available in public domain. }\end{array}$ & 4 \\
\hline $\begin{array}{l}\text { Work Limitation Question- } \\
\text { naire (WLQ) [55-56] }\end{array}$ & $\begin{array}{l}\text { 1. Work-related time management } \\
\text { 2. Physical demands } \\
\text { 3. Interpersonal/mental demands } \\
\text { 4. Output demands }\end{array}$ & $\begin{array}{l}\text { Evaluates level of limitation patient is experiencing in workplace } \\
\text { due to health problems. Patient reports his/her ability or inability to } \\
\text { execute work tasks and related loss of productivity. Available upon } \\
\text { request. }\end{array}$ & $\begin{array}{l}25 \text { (8-item } \\
\text { version also } \\
\text { available) }\end{array}$ \\
\hline $\begin{array}{l}\text { Work Productivity and } \\
\text { Activity Impairment } \\
\text { (WPAI) [57] }\end{array}$ & $\begin{array}{l}\text { 1. Hours absent from work because of health issues } \\
\text { 2. Hours absent for other reasons } \\
\text { 3. Hours worked } \\
\text { 4. Effect of health on productivity } \\
\text { 5. Effect of health on productivity outside of work }\end{array}$ & $\begin{array}{l}\text { Assesses effect of health problems on work productivity. Available } \\
\text { in public domain. }\end{array}$ & 6 \\
\hline $\begin{array}{l}\text { Social Adjustment Scale } \\
\text { (SAS-SR) [58] }\end{array}$ & $\begin{array}{l}\text { 1. Work } \\
\text { 2. Social/leisure activities } \\
\text { 3. Relationships with extended family } \\
\text { 4. Roles as spouse, parent, and member of family unit } \\
\text { 5. Financial }\end{array}$ & $\begin{array}{l}\text { Self-report that allows routine assessment of patient's social adjust- } \\
\text { ment, especially in case of depression. It is also useful method as part } \\
\text { of detection of even mild depressions, regular aftercare evaluation of } \\
\text { outpatients, or as outcome measure in longitudinal studies. Available } \\
\text { for purchase. }\end{array}$ & 54 \\
\hline $\begin{array}{l}\text { Dyadic Adjustment Scale } \\
\text { (DAS) [59] }\end{array}$ & $\begin{array}{l}\text { 1. Dyadic satisfaction } \\
\text { 2. Dyadic cohesion } \\
\text { 3. Dyadic consensus } \\
\text { 4. Affectional expression }\end{array}$ & $\begin{array}{l}\text { Self-report measure of relationship adjustment. 5-10 min to adminis- } \\
\text { ter. Can also be adapted into interview format. Available for purchase. }\end{array}$ & 32 \\
\hline $\begin{array}{l}\text { Life Stressors and Social } \\
\text { Resources Inventory } \\
\text { (LISRES) [60] }\end{array}$ & $\begin{array}{l}\text { 1. Physical health } \\
\text { 2. Spouse/partner } \\
\text { 3. Finances } \\
\text { 4. Work } \\
\text { 5. Home/neighborhood } \\
\text { 6. Children } \\
\text { 7. Friends and social activities } \\
\text { 8. Extended family }\end{array}$ & $\begin{array}{l}\text { Self-report measure that gauges ongoing life stressors and social } \\
\text { resources as well as changes over time. Available for purchase. }\end{array}$ & 200 \\
\hline
\end{tabular}


Table. (cont)

Measures of functional impairment and quality of life.

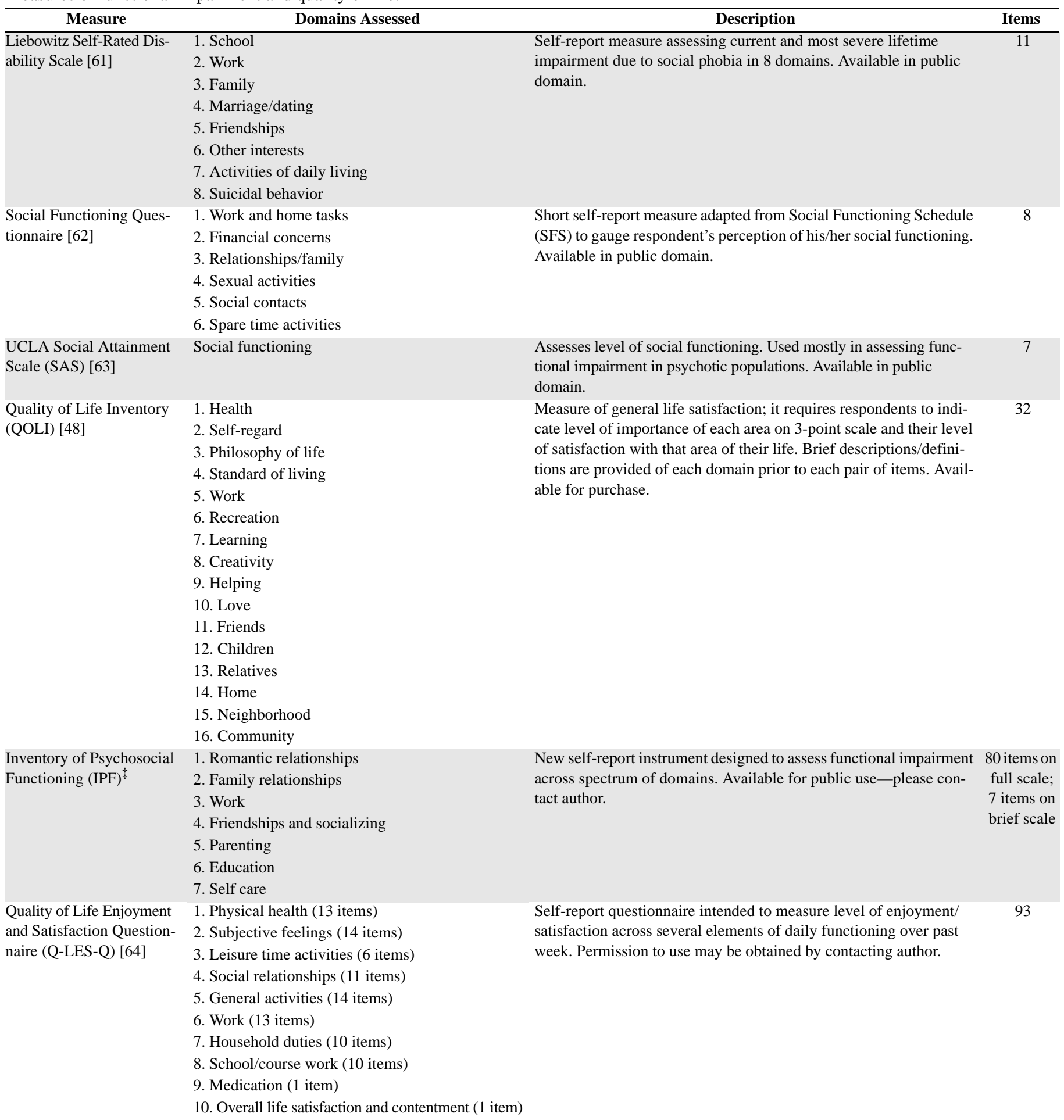

*Sheehan DV. Sheehan Work Disability Scale. 1983. Unpublished instrument.

${ }^{\dagger}$ Sheehan DV. Sheehan Disability Scale (SDS-W). 2003. Unpublished instrument.

${ }^{\ddagger}$ Marx BP, Schnurr P, Rodriguez P, Holowka DW, Lunney C, Weathers F, Sloan D, Keane TM. Development and validation of a scale to assess functional impairment among active duty service members and veterans. Proceedings of the 25th Annual Meeting of the International Society for Traumatic Stress Studies; 2009 Nov 5-7; Atlanta, GA. 
for Diagnostic and Statistical Manual of Mental Disorders, Fourth Edition, Text Revision (DSM-IV-TR), PTSD module [66] both contain questions designed to assess impairment more generally within social and occupational domains. A limitation of using this method of assessing functional impairment is that clinicians are unable to obtain more specific information about an individual's functioning across a number of different psychosocial domains (e.g., intimate relationships, parenting, friendships, occupational performance, self-care).

A more detailed assessment, on the other hand, provides an opportunity to explore the extent to which specific PTSD and other stress-related disorder symptoms are affecting specific areas of functioning. During a detailed assessment, the clinician can pose additional questions by psychosocial domain, thereby providing a better overview of the quality of multiple systems in the individual's life.

In order to more accurately assess a broad range of impairment, researchers have developed more comprehensive, standardized interviews to assess psychosocial functioning. A good example of one such instrument is the WHO Disability Assessment Schedule II (WHODAS-II) [50]. The WHODAS-II was developed to assess disability related to physical and psychiatric disorders experienced within the past 30 days and provides a profile of functioning across six activity domains-understanding and communicating, mobility, self-care, getting along with others, life activities, and participation in society-as well as an overall disability score. The WHODAS-II has been used with individuals with PTSD and other stress-related disorders; research has shown it to be useful in these populations [67-71]. A notable asset of the WHODAS-II is its relationship with the International Classification of Functioning, Disability, and Health [72], an internationally recognized system of classifying the consequences of physical and mental health conditions. The WHO has also developed and validated a self-report version of the WHODAS-II that can be used in instances when an interview is not feasible or efficient [50].

The Longitudinal Interval Follow-Up Evaluation (LIFE) [73] is also a standardized interview that was designed to assess the long-term course and effects of psychiatric disorders. Like the WHODAS-II, it evaluates and provides the clinician with information about an individual's functioning across multiple domains (e.g., work, relationships, sexual, household, recreation) as well as providing a global social adjustment score. Research has shown the LIFE to be useful when used with individuals with PTSD and other stress-related disorders [74-75].

\section{Self-Report Measures}

Currently, there are a number of self-report instruments available for use as part of an assessment battery (Table). In selecting a self-report instrument, clinicians may wish to consider the relative strengths and limitations of each scale. With respect to specific use with Veterans and/or servicemembers, most of these scales do not have norm-referenced scoring available. In addition, when assessing functional impairment, it is important to choose a measure that is not only valid and reliable but also sensitive to changes within individuals over time. This is necessary in order to detect minimal clinically important differences. Guyatt et al. have used the term "responsiveness" to describe a measure's ability to detect change within individuals over time [76]. Although, in general, reliable measures are likely to be responsive, the conventional method of assessing reliability using the correlation relating between-person variance to total variance may be misleading if it is used as the only index of reliability. As such, it is possible for instruments to be reliable but unresponsive to change; conversely, instruments may show poor reliability but excellent response to change over time [76]. Guyatt et al. suggested using an index of responsiveness, defined as an intraclass correlation coefficient that can be calculated as the ratio of the variance in participants' scores attributable to characteristics of the participant to the total variance in score (including variance attributable both to between-subject differences and to differences for the same subject over multiple repetitions of the instrument) [76]. This intraclass coefficient provides information about the extent to which multiple administrations of the instrument yield the same values under the same conditions in the same individuals [76]. To address this and other limitations of the available self-report instruments (e.g., difficulty in scoring, requiring causal attributions on the part of the respondent), we are developing a new measure of functional impairment: the Inventory of Psychosocial Functioning (IPF). This instrument has been created by the authors of this article in collaboration with several experts in PTSD and functional impairment among Veterans and servicemembers. The IPF was developed by first defining and systematically operationalizing each of the variables representing functional impairment. This objective was accomplished using a rational, classical test theory-oriented approach to instrument development. We then collected data from an initial test development sample 
of Veterans and conducted first-stage psychometric analyses. Item and scale characteristics were derived and scrutinized to refine the item sets for optimal internal consistency and reliability, as appropriate. We are now in the process of crossvalidating results from the initial test development using several independent samples.

The IPF has both full (80 items) and brief (7 items) versions. The full IPF assesses impairment within the last 30 days across multiple psychosocial domains of functioning with sufficient breadth and depth without requiring respondents to make attributions regarding the cause of the impairments. Respondents answer each item by using a 7point scale ranging from 1 (“never”) to 7 (“always”). The IPF yields an overall functional impairment score as well as scores for seven domains: romantic relationships, family relationships, work, friendships and socializing, parenting, academic pursuits, and self-care. Higher scores indicate greater functional impairment. Because functioning over the past 30 days is assessed, respondents are instructed to skip sections of the instrument that are not currently relevant. Respondents take approximately 7 to 12 minutes to complete the full IPF, depending on the number of questions answered. The psychometric properties of the full IPF are being tested using several independent Veteran and servicemember samples.

Data collected from 457 Veterans show that the IPF has excellent reliability, based on the guidelines suggested by Cicchetti [77]. The IPF demonstrates excellent internal consistency, with a Cronbach alpha coefficient of 0.93 for the entire scale. The IPF subscales demonstrate good internal consistency, with Cronbach alphas ranging from 0.80 to 0.90 . Additionally, the corrected item-total correlations by subscale range from $r=0.18$ to $r=0.78$. The overall mean IPF score for this sample is 3.27 (standard deviation $[\mathrm{SD}]=0.95$ ). The mean impairment scores (M) and SDs for each of the IPF scales are as follows: romantic relationships: $\mathrm{M}=3.18, \mathrm{SD}=1.03$; family: $\mathrm{M}=3.64, \mathrm{SD}=1.33$; work: $\mathrm{M}=2.31$, $\mathrm{SD}=0.88$; friendships and socializing: $\mathrm{M}=3.19, \mathrm{SD}=1.22$; parenting: $\mathrm{M}=2.74, \mathrm{SD}=1.14$; education: $\mathrm{M}=2.80, \mathrm{SD}=$ 0.934; self care: $\mathrm{M}=3.36, \mathrm{SD}=1.11$.

The overall IPF score correlates significantly with a number of other self-report measures of impairment and QOL, such as the WHODAS-II $(r=0.71)$, the Medical Outcomes Study 36-Item Short Form for Veterans $(r=$ $0.68)$, the Sheehan Disability Scale $(r=0.53-0.57)$, and the QOL Inventory $(r=0.59$ ) (all $p<0.001$ ). Scores on the social and interpersonal IPF scales (i.e., romantic relationships, family, friendships and socializing, parenting) correlate significantly with similar subscales on other measures, with correlations ranging from $r=0.30$ to $r=0.61$ (all $p<0.001$ ). Scores on the work and education IPF scales correlate significantly with scores on other similar scales, with correlations ranging from $r=$ 0.38 to $r=0.60$ (all $p<0.001$ ). Scores on the IPF SelfCare subscale correlate significantly with several similar subscales in other measures, with correlations ranging from $r=0.39$ to $r=0.62$ (all $p<0.01$ ). The overall IPF score correlates significantly with PTSD symptom severity, $r=0.48, p<0.001$, assessed using the CAPS for DSM-IV-TR. Similarly, participants meeting diagnostic criteria for PTSD had significantly greater overall IPF scores $(\mathrm{M}=3.90, \mathrm{SD}=0.99)$ than participants who did not meet diagnostic criteria for PTSD $(\mathrm{M}=3.08$, SD = $0.82), t(283)=-7.04, p<0.001$. The overall IPF score also correlates significantly $(r=0.53, p<0.01)$ with major depression symptom severity assessed using the module for major depressive episode (current) from the Mini-International Neuropsychiatric Interview. Similarly, relative to participants who did not meet diagnostic criteria for major depressive disorder $(\mathrm{M}=2.89, \mathrm{SD}=0.74)$, participants who met diagnostic criteria for major depressive disorder had significantly greater overall IPF scores $(\mathrm{M}=3.78, \mathrm{SD}=0.93), t(281)=-8.97, p<0.001$.

\section{Idiographic Assessment}

In addition to using well-validated interviews and self-report instruments, consistent with the CPG, we recommend that clinicians ask clients to provide a narrative description in their own words of changes within all relevant psychosocial domains of functioning. Doing so will allow the clinician to obtain more idiographic information about the nature of an individual's functional impairment. Following the patient's description, clinicians may ask about the subjective importance of each functional domain. For example, if a person is not performing occupational duties well, the clinician could ask, "How important is it for you to do your job well?" and "Was your job always important to you?” If the individual indicates that it is indeed important to perform his or her job duties well, then occupational functioning ought to be considered in treatment planning.

Next, it is important that clinicians determine whether the noted impairment is trauma-related. One of the techniques most helpful in determining whether an existing impairment is related to the stressor exposure is asking 
explicitly about time of onset. Such questions can be worded simply, such as "When did you start having arguments with your wife? Did it start (or get worse) after [the event]?” In order for impairment to be potentially related to the stressor exposure, it must have either had an onset or worsened after the event. It is important to note that clinicians may wish to use caution in using the time of onset as the only indicator of whether the impairment is traumarelated or not. Time of onset is only a partial indicator. The clinician may wish to ask the Veteran if there are any other issues that could be associated with the impairment. For instance, domestic arguments could be more closely related to intoxication or other co-occurring conditions even if trauma exposure preceded their onset.

Once key functional impairments are identified and clearly linked to the index event, clinicians can ask more specific questions about the nature of the impairments and how the noted impairments are related to specific PTSD or other stress disorder-related symptoms. Furthermore, we suggest that clinicians identify which areas are relevant to each client (e.g., if the individual has children, then the clinician may wish to inquire about functioning in the parenting domain). One way to ask is, "How has your relationship with [your children] changed since the event?” This sample question can be adapted to assess other domains of functioning as necessary.

\section{DISCUSSION: IMPORTANT CONSIDERATIONS WHEN ASSESSING FUNCTIONAL IMPAIRMENT}

\section{Limitations of Current Diagnostic Classification System}

In order to meet diagnostic criteria for PTSD and other disorders currently listed in the DSM-IV-TR, an individual must not only endorse the requisite number of PTSD symptoms but also report that these symptoms have resulted in "clinically significant distress or impairment in social, occupational, or other important areas of functioning” [78]. Although this criterion is satisfied by the report of either distress or impairment, it is unlikely for one to be present without the other. Although this still could change, the DSM-5 work group is aiming to maintain the clinical significant criterion part of the revised PTSD diagnostic criteria [79-80].

Data from our ongoing study has revealed strong, significant correlations between Veterans' self-rated level of functional impairment across several psychosocial domains (e.g., romantic relationships, family, parenting, friendships and socializing, work, education, self-care) and self-reported distress. Specifically, correlations between self-reported functional impairment and distress ranged from $r=0.70$ to $r=0.88(p<0.001)$. Our findings suggest that clinicians may wish to consider the likelihood that dysfunction and distress usually go hand in hand. That being said, our findings also suggest that there may indeed be instances in which levels of dysfunction and distress may be incongruous among clients. This is precisely why a detailed and comprehensive assessment of functional assessment is necessary.

Another important point for clinicians to keep in mind is that functional impairment is not exclusive to individuals meeting full diagnostic criteria for PTSD or other stress-related disorders. Individuals who may be subthreshold, diagnostically speaking, or who report only some symptoms of a given disorder may also experience substantially impaired functioning [81-82]. One study found that individuals with PTSD evidenced 30 percent greater overall impairment in social, occupational, and family functioning compared with a group with subthreshold PTSD. Nonetheless, the subthreshold group also experienced substantial impairment, approximately four times greater than those without PTSD [82]. Other studies have found that individuals with partial PTSD showed levels of impairment similar to individuals who met full criteria [83], and those with full or subthreshold PTSD had similar degrees of social and work impairment [84].

Although functional impairment has been used by some researchers to refer more broadly to limitations in social and occupational spheres of life [85], DSM-IV-TR criteria do not make it clear how the symptoms may affect social, occupational, or other important areas of functioning, thereby making it difficult for clinicians to have a clear sense of what types of changes to look for in their assessments. Although the DSM-IV-TR states that symptoms must cause clinically significant distress or impairment in social, occupational, or other areas of functioning, the DSM-IV-TR does not specify what is meant by "clinically significant." This makes assessing the clinical significance criterion more difficult and requires a judgment on the part of the clinician. The DSM-IV-TR provides the Global Assessment of Functioning (GAF) as a tool for clinicians to assess the level of functioning. However, the GAF score has limited utility in the assessment of PTSD-related impairment for Veterans. The GAF score is only minimally relevant to PTSD because of its emphasis on the symptoms of mood 
disorders and schizophrenia and its limited range of symptom content [86]. Another limitation associated with using the GAF identified by the Institute of Medicine (IOM) [87] is that, even though it combines symptomatology and social-occupational functioning into one score [88], these constructs may be distinct. Additionally, because the GAF is a single-item measure, its psychometric properties show mixed findings [89]. Given that the methods by which we measure psychiatric-related functional impairment have critical value from a healthcare perspective in terms of identifying individuals with the disorder and for promoting more efficient allocation of resources and efforts toward those who are in most need, the IOM committee recommended that the VA ultimately identify and implement an appropriate replacement for the GAF, although they did not specifically identify any such replacement [86].

\section{Obtaining Collateral Reports}

We suggest clinicians consider obtaining collateral information from family members and other third parties to determine the extent to which an individual's selfreported impairments rise to the level of clinical significance. Collateral information can be obtained by simply asking a spouse or family member (or any other individual who is close to the Veteran) to complete the same measure administered to the Veteran (e.g., the WHODAS-II) but instructing the spouse or family member to answer the questions based on their perception of how the Veteran is doing in each of those domains.

\section{Concerns About Response Bias}

Another important consideration is that some Veterans may exaggerate or even malinger symptoms of PTSD and associated functional impairment to support or maintain a claim for PTSD service-connection disability [90-91]. As such, any assessment protocol for assessing PTSD and associated impairments should include measures of response bias to assess overreporting or malingering. Possible measures include the Minnesota Multiphasic Personality Inventory-2 [92], Structured Inventory of Malingered Symptomatology [93], or Miller Forensic Assessment of Symptoms Test [94]. It is important, however, to keep in mind that no single measure is ideal for identifying those who malinger PTSD symptoms and that elevations on such indicators are not necessarily caused by intentional efforts to "fake bad" [95]. Additional possibilities for exaggerated profiles may be that such individuals are in greater distress or subjectively feel more distress than other patients [96-98].

\section{Distinguishing Impairment from Symptomatology}

It is not surprising that past research has shown an association between PTSD and functional impairment: these two constructs are conceptually intertwined. Generally speaking, a condition or behavior would not be labeled as a symptom if it were not causing some sort of difficulty. Nonetheless, the focus on impairment itself as an outcome is relatively new to the field. Beginning in 1980, with DSM, Third Edition [99], significant distress or functional impairment was formally considered a necessary criterion for psychiatric disorder.

The current CPG clearly directs clinicians to assess functioning as an important part of the clinical picture and as a necessary condition for diagnosis. Because functioning is largely defined in terms of social and occupational functioning, it is easy to see how many PTSD symptoms can lead to difficulties in performing social or work roles. As mentioned earlier, symptoms of numbing could easily lead to relationship difficulties, and it is easy to imagine how angry outbursts could cause trouble at work. However, in some cases it can be more difficult to distinguish the symptom from the impairment it causes. For instance, "difficulty concentrating" will only be evident if it disrupts some meaningful activity, and thus the impairment is more readily apparent but is effectively subsumed within the symptom. In contrast, other symptoms may be more egosyntonic and thus are less likely to be identified as impaired functioning by the patient. For instance, when asked whether they "make a special effort to avoid activities, people, or places" that remind them of the trauma, many Veterans reply that they have been avoiding reminders for so long that it no longer requires any effort at all. In such cases, although the symptom is not perceived as distressing, the impairment associated with it (i.e., withdrawal from meaningful activities) may be of clinical concern and thus important to assess. Finally, some symptoms may cause only transient or insignificant distress or impairment, and in such cases, it is unclear to what extent these symptoms ought to be considered in the diagnosis of PTSD or other stress-related disorders. The DSM-IV-TR simply suggests that the "symptoms cause significant distress or impairment," but in practice clinicians do not routinely assess the relative impairment of each symptom in order to determine whether it should be counted toward a diagnosis. Rather, most clinicians are more likely to 
assess overall level of functioning even though a more detailed assessment may provide a more accurate diagnosis and a better treatment plan.

Given that comorbidity is common, some patients may have difficulty determining the extent to which their psychosocial difficulties are due to PTSD symptoms versus depression or substance abuse. In other cases, however, patients can be quite insightful about such differences, and thus we recommend asking them to provide a clearer picture whenever possible; however, these data ought to be interpreted with caution.

It is also important to note that, for some individuals, symptoms may only lead to impairment in certain contexts. In fact, it is widely believed that not only are certain symptoms normal, but under battlefield conditions, some of the behaviors frequently considered symptomatic are actually quite adaptive. For instance, it is not difficult to see how hypervigilance, efforts to avoid situations that may be harmful, and clear memories of past dangerous situations may in fact help keep military personnel alive and are therefore quite functional in the context of a war zone. Nonetheless, it is also understandable how such behaviors can lead to impairments in civilian life. Thus, the context and circumstances of the patient's life must be taken into account. This is where diligent assessment of functional impairment serves the crucial role of determining what constitutes a problem or symptom worthy of clinical attention.

\section{Client's Personal Characteristics and Environmental Circumstances}

While conducting assessments of functioning, it is important to remember that we may sometimes make assumptions of what can be reasonably expected of individuals based on relatively little information. Such assumptions must be checked against the client's history or selfreport to avoid jumping to conclusions based on superficial data, which could lead to over- or underestimating past or future functioning without a solid basis in fact. Comparing one soldier to another may also be problematic. Although it may be easy at times to assume similar abilities among an ostensibly homogeneous cohort, we urge caution in making such assumptions and always encourage direct assessment.

Another related, but less conspicuous, pitfall in the assessment of functional impairment is that the metric by which we determine impairment may affect our overall assessment and may not be readily apparent. The simplest point of comparison is likely to the individual's level of functioning prior to the trauma, if such information is available. If not, self- or other report may be helpful in determining whether a decline in functioning has occurred. However, in cases where military personnel are younger, functional impairment may be more evident in terms of a deviation from expected developmental trajectories. For instance, failure to attend college would certainly not indicate impairment in the majority of the population, but for someone who had previously been an honor student with aspirations of graduate school, this could indicate a serious level of impairment. Thus, an inability to achieve goals that would previously have been thought well within reach could also be clinically meaningful.

\section{CONCLUSIONS}

VA and DOD's renewed focus on functional impairment in the assessment of stress-related disorders is encouraging. Although a necessary condition for a DSMIV-TR diagnosis, functional impairment is all too often overlooked or given only cursory evaluation. Nonetheless, functional impairment is clearly important, perhaps even more so than other criteria given its status as a straightforward outcome. Although symptomatology may be the substance of the disorder, impairment defines its form. Ultimately, functional impairment may be the outcome we are most interested in ameliorating, and thus, paying specific attention to its assessment is crucial.

What we have provided here hopefully serves as a valuable companion to the CPG, drawing attention to issues that may complicate the assessment of functional impairment and providing more specific guidelines for its execution. We recommend a multimethod assessment of functional impairment using clinical interviews, self-report instruments, and narratives to collect broad functioning information and information within specific domains. We also suggest that information obtained via patient selfreport or clinician rating be supplemented with data from friends, family members, coworkers, supervisors, or teachers to provide a more complete picture of current and premorbid functional status. Although these corroborating reports are also subjective, when combined with other data, they may strengthen the resulting conclusions.

Clearly, further research is necessary in this area to improve our methods of assessing functional impairment, to further evaluate risk and resilience factors for impaired 
functioning, and to explore treatment approaches that maximize gains in functional outcomes. Finally, it is our belief that continued implementation of the CPG recommendations will lead to further research in this area, as well as improved treatment for Active Duty military and Veterans alike.

\section{ACKNOWLEDGMENTS}

\section{Author Contributions:}

Study concept and design: B. P. Marx.

Acquisition of data: B. P. Marx, P. Rodriguez, D. W. Holowka. Analysis and interpretation of data: B. P. Marx, P. Rodriguez, D. W. Holowka.

Drafting of manuscript: B. P. Marx, P. Rodriguez, D. W. Holowka. Critical revision of manuscript for important intellectual content: B. P. Marx, P. Rodriguez, D. W. Holowka.

Statistical analysis: B. P. Marx, P. Rodriguez, D. W. Holowka. Obtained funding: B. P. Marx.

Administrative, technical, or material support: B. P. Marx, P. Rodriguez. Study supervision: B. P. Marx.

Financial Disclosures: The authors have declared that no competing interests exist.

Funding/Support: This material was based on work supported by award W81XWH-08-2-0028 from the DOD to Brian P. Marx. Institutional Review: The researchers obtained approval for the use of the IPF from their local institutional review boards (i.e., Boston VA Healthcare System; VA Pacific Islands Healthcare System, Human Research Protections Office).

\section{REFERENCES}

1. Holowka DW, Marx BP. Assessing PTSD-related functional impairment and quality of life. In: Beck GJ, Sloan DM, editors. Oxford handbook of traumatic stress disorders. New York (NY): Oxford University Press; 2011.

2. Bolton D, Hill J, O’Ryan D, Udwin O, Boyle S, Yule W. Long-term effects of psychological trauma on psychosocial functioning. J Child Psychol Psychiatry. 2004;45(5):1007-14. [PMID:15225342] http://dx.doi.org/10.1111/j.1469-7610.2004.t01-1-00292.x

3. Hoge CW, McGurk D, Thomas JL, Cox AL, Engel CC, Castro CA. Mild traumatic brain injury in U.S. soldiers returning from Iraq. N Engl J Med. 2008;358(5):453-63. [PMID:18234750] http://dx.doi.org/10.1056/NEJMoa072972

4. Resnick SG, Rosenheck RA. Integrating peer-provided services: a quasi-experimental study of recovery orientation, confidence, and empowerment. Psychiatr Serv. 2008;59(11): 1307-14. [PMID:18971407] http://dx.doi.org/10.1176/appi.ps.59.11.1307
5. Rona RJ, Jones M, Iversen A, Hull L, Greenberg N, Fear NT, Hotopf M, Wessely S. The impact of posttraumatic stress disorder on impairment in the UK military at the time of the Iraq war. J Psychiatr Res. 2009;43(6):649-55. [PMID:18950801] http://dx.doi.org/10.1016/j.jpsychires.2008.09.006

6. Smith MW, Schnurr PP, Rosenheck RA. Employment outcomes and PTSD symptom severity. Ment Health Serv Res. 2005;7(2):89-101. [PMID:15974155] http://dx.doi.org/10.1007/s11020-005-3780-2

7. Kuhn E, Blanchard EB, Hickling EJ. Posttraumatic stress disorder and psychosocial functioning within two samples of MVA survivors. Behav Res Ther. 2003;41(9):1105-12. [PMID:12914811] http://dx.doi.org/10.1016/S0005-7967(03)00071-8

8. Sayers SL, Farrow VA, Ross J, Oslin DW. Family problems among recently returned military veterans referred for a mental health evaluation. J Clin Psychiatry. 2009;70(2): 163-70. [PMID:19210950] http://dx.doi.org/10.4088/JCP.07m03863

9. Cohen E, Zerach G, Solomon Z. The implication of combat-induced stress reaction, PTSD, and attachment in parenting among war veterans. J Fam Psychol. 2011;25(5): 688-98. [PMID:21639634] http://dx.doi.org/10.1037/a0024065

10. Solomon Z, Debby-Aharon S, Zerach G, Horesh D. Marital adjustment, parental functioning, and emotional sharing in war veterans. J Fam Issues. 2011;32(1):127-47. http://dx.doi.org/10.1177/0192513X10379203

11. Laffaye C, Cavella S, Drescher K, Rosen C. Relationships among PTSD symptoms, social support, and support source in veterans with chronic PTSD. J Trauma Stress. 2008; 21(4):394-401. [PMID:18720391] http://dx.doi.org/10.1002/jts.20348

12. O’Connell MJ, Kasprow W, Rosenheck RA. Rates and risk factors for homelessness after successful housing in a sample of formerly homeless veterans. Psychiatr Serv. 2008; 59(3):268-75. [PMID:18308907] http://dx.doi.org/10.1176/appi.ps.59.3.268

13. Schnurr PP, Hayes AF, Lunney CA, McFall M, Uddo M. Longitudinal analysis of the relationship between symptoms and quality of life in veterans treated for posttraumatic stress disorder. J Consult Clin Psychol. 2006;74(4): 707-13. [PMID:16881778] http://dx.doi.org/10.1037/0022-006X.74.4.707

14. Shea MT, Vujanovic AA, Mansfield AK, Sevin E, Liu F. Posttraumatic stress disorder symptoms and functional impairment among OEF and OIF National Guard and Reserve veterans. J Trauma Stress. 2010;23(1):100-107. [PMID:20127726]

15. Pietrzak RH, Johnson DC, Goldstein MB, Malley JC, Rivers AJ, Morgan CA, Southwick SM. Psychosocial buffers of 
traumatic stress, depressive symptoms, and psychosocial difficulties in veterans of Operations Enduring Freedom and Iraqi Freedom: the role of resilience, unit support, and postdeployment social support. J Affect Disord. 2010;120(1-3): 188-92. [PMID:19443043] http://dx.doi.org/10.1016/j.jad.2009.04.015

16. Management of Post-Traumatic Stress Working Group [Internet]. VA/DoD clinical practice guideline for management of posttraumatic stress. Washington (DC): Department of Veterans Affairs, Department of Defense; 2010. Available from: http://www.healthquality.va.gov/ptsd.ptsd_full.pdf

17. Taft CT, Watkins LE, Stafford J, Street AE, Monson CM. Posttraumatic stress disorder and intimate relationship problems: a meta-analysis. J Consult Clin Psychol. 2011; 79(1):22-33. [PMID:21261431] http://dx.doi.org/10.1037/a0022196

18. Schnurr PP, Lunney CA, Bovin MJ, Marx BP. Posttraumatic stress disorder and quality of life: extension of findings to veterans of the wars in Iraq and Afghanistan. Clin Psychol Rev. 2009;29(8):727-35. [PMID:19744758] http://dx.doi.org/10.1016/j.cpr.2009.08.006

19. Sayer N, Carlson K, Schnurr P. Assessment of functioning and disability. In: Benedek DM, Wynn GH, editors. Clinical manual for management of PTSD. Arlington (VA): American Psychiatric Publishing; 2011. p. 255-87.

20. Norman SB, Stein MB, Davidson JR. Profiling posttraumatic functional impairment. J Nerv Ment Dis. 2007; 195(1):48-53. [PMID:17220739] http://dx.doi.org/10.1097/01.nmd.0000252135.25114.02

21. Sautter FJ, Glynn SM, Thompson KE, Franklin L, Han X. A couple-based approach to the reduction of PTSD avoidance symptoms: preliminary findings. J Marital Fam Ther. 2009;35(3):343-49. [PMID:19522786] http://dx.doi.org/10.1111/j.1752-0606.2009.00125.x

22. Riggs DS, Byrne CA, Weathers FW, Litz BT. The quality of the intimate relationships of male Vietnam veterans: problems associated with posttraumatic stress disorder. J Trauma Stress. 1998;11(1):87-101. [PMID:9479678] http://dx.doi.org/10.1023/A:1024409200155

23. Solomon Z, Dekel RR, Mikulincer MM. Complex trauma of war captivity: a prospective study of attachment and post-traumatic stress disorder. Psychol Med. 2008;38(10): 1427-34. [PMID:18257940] http://dx.doi.org/10.1017/S0033291708002808

24. Solomon Z, Dekel R, Zerach G. The relationships between posttraumatic stress symptom clusters and marital intimacy among war veterans. J Fam Psychol. 2008;22(5):659-66. [PMID:18855502] http://dx.doi.org/10.1037/a0013596

25. Monson CM, Taft CT, Fredman SJ. Military-related PTSD and intimate relationships: from description to theory-driven research and intervention development. Clin Psychol Rev.
2009;29(8):707-14. [PMID:19781836]

http://dx.doi.org/10.1016/j.cpr.2009.09.002

26. Meis LA, Erbes CR, Polusny MA, Compton JS. Intimate relationships among returning soldiers: the mediating and moderating roles of negative emotionality, PTSD symptoms, and alcohol problems. J Trauma Stress. 2010;23(5): 564-72. [PMID:20848617] http://dx.doi.org/10.1002/jts.20560

27. Baptist J, Amanor-Boadu Y, Garrett K, Nelson Goff BS, Collum J, Gamble P, Gurss H, Sanders-Hahs E, Strader L,Wick S. Military marriages: The aftermath of Operation Iraqi Freedom (OIF) and Operation Enduring Freedom (OEF) deployments. Contemp Fam Ther. 2011;33(3):199-214. http://dx.doi.org/10.1007/s10591-011-9162-6

28. Galovski T, Lyons J. Psychological sequelae of combat violence: A review of the impact of PTSD on the veteran's family and possible interventions. Aggress Violent Behav. 2004;9(5):477-501. http://dx.doi.org/10.1016/S1359-1789(03)00045-4

29. Leen-Feldner EW, Feldner MT, Bunaciu L, Blumenthal H. Associations between parental posttraumatic stress disorder and both offspring internalizing problems and parental aggression within the National Comorbidity Survey-Replication. J Anxiety Disord. 2011;25(2):169-75. [PMID:20880666] http://dx.doi.org/10.1016/j.janxdis.2010.08.017

30. Gewirtz AH, Polusny MA, DeGarmo DS, Khaylis A, Erbes CR. Posttraumatic stress symptoms among National Guard soldiers deployed to Iraq: associations with parenting behaviors and couple adjustment. J Consult Clin Psychol. 2010;78(5):599-610. [PMID:20873896] http://dx.doi.org/10.1037/a0020571

31. Ruscio AM, Weathers FW, King LA, King DW. Male warzone veterans' perceived relationships with their children: the importance of emotional numbing. J Trauma Stress. 2002;15(5):351-57. [PMID:12392222] http://dx.doi.org/10.1023/A:1020125006371

32. Banyard V, Potter S, Turner H. The impact of interpersonal violence in adulthood on women's job satisfaction and productivity: The mediating roles of mental and physical health. Psychol Violence. 2011;1(1):16-28. http://dx.doi.org/10.1037/a0021691

33. Cowls J, Galloway E. Understanding how traumatic reenactment impacts the workplace: assisting clients' successful return to work. Work. 2009;33(4):401-11. [PMID:19923663]

34. Heir T, Piatigorsky A, Weisæth L. Posttraumatic stress symptom clusters associations with psychopathology and functional impairment. J Anxiety Disord. 2010;24(8):936-40. [PMID:20638820] http://dx.doi.org/10.1016/j.janxdis.2010.06.020

35. Morin CM. Chronic insomnia: Recent advances and innovations in treatment developments and dissemination. Can 
Psychol. 2010;51(1):31-39.

http://dx.doi.org/10.1037/a0018715

36. Daley M, Morin CM, LeBlanc M, Grégoire JP, Savard J, Baillargeon L. Insomnia and its relationship to health-care utilization, work absenteeism, productivity and accidents. Sleep Med. 2009;10(4):427-38. [PMID:18753000]

http://dx.doi.org/10.1016/j.sleep.2008.04.005

37. Fernandez-Mendoza J, Calhoun S, Bixler EO, Pejovic S, Karataraki M, Liao D, Vela-Bueno A, Ramos-Platon MJ, Sauder KA, Vgontzas AN. Insomnia with objective short sleep duration is associated with deficits in neuropsychological performance: a general population study. Sleep. 2010;33(4): 459-65. [PMID:20394314]

38. Vinokur AD, Pierce PF, Lewandowski-Romps L, Hobfoll SE, Galea S. Effects of war exposure on air force personnel's mental health, job burnout and other organizational related outcomes. J Occup Health Psychol. 2011;16(1):3-17.

[PMID:21280941]

http://dx.doi.org/10.1037/a0021617

39. Margolin G, Vickerman KA. Posttraumatic stress in children and adolescents exposed to family violence: I. Overview and issues. Couple Family Psychol. 2011;1(S):163-73.

40. Parto JA, Evans MK, Zonderman AB. Symptoms of posttraumatic stress disorder among urban residents. J Nerv Ment Dis. 2011;199(7):436-39. [PMID:21716054] http://dx.doi.org/10.1097/NMD.0b013e3182214154

41. Washington DL, Yano EM, McGuire J, Hines V, Lee M, Gelberg L. Risk factors for homelessness among women veterans. J Health Care Poor Underserved. 2010;21(1):82-91. [PMID:20173257] http://dx.doi.org/10.1353/hpu.0.0237

42. Tessler R, Rosenheck R, Gamache G. Gender differences in self-reported reasons for homelessness. J Soc Distress Homeless. 2001;10(3):243-54. http://dx.doi.org/10.1023/A:1016688707698

43. Galea S, Tracy M, Norris F, Coffey SF. Financial and social circumstances and the incidence and course of PTSD in Mississippi during the first two years after Hurricane Katrina. J Trauma Stress. 2008;21(4):357-68.

[PMID:18720399]

http://dx.doi.org/10.1002/jts.20355

44. Koenen KC, Stellman SD, Sommer JF Jr, Stellman JM. Persisting posttraumatic stress disorder symptoms and their relationship to functioning in Vietnam veterans: a 14-year follow-up. J Trauma Stress. 2008;21(1):49-57.

[PMID:18302174] http://dx.doi.org/10.1002/jts.20304

45. Taylor S, Wald J, Asmundson GJ. Factors associated with occupational impairment in people seeking treatment for posttraumatic stress disorder. Can J Commun Ment Health. 2006;25(2):289-301.
46. Harding KJ, Rush AJ, Arbuckle M, Trivedi MH, Pincus HA. Measurement-based care in psychiatric practice: a policy framework for implementation. J Clin Psychiatry. 2011; 72(8):1136-43. [PMID:21295000] http://dx.doi.org/10.4088/JCP.10r06282whi

47. WHOQOL Group. The World Health Organization quality of life assessment (WHOQOL): development and general psychometric properties. Soc Sci Med. 1998;46(12):1569-85.

[PMID:9672396] http://dx.doi.org/10.1016/S0277-9536(98)00009-4

48. Frisch MB, Cornell J, Villanueva M, Retzlaff PJ. Clinical validation of the Quality of Life Inventory. A measure of life satisfaction for use in treatment planning and outcome assessment. Psychol Assess. 1992;4(1):92-101. http://dx.doi.org/10.1037/1040-3590.4.1.92

49. Diener E, Emmons RA, Larsen RJ, Griffin S. The Satisfaction With Life Scale. J Pers Assess. 1985;49(1):71-75. [PMID:16367493] http://dx.doi.org/10.1207/s15327752jpa4901 13

50. World Health Organization. WHO Psychiatric Disability Assessment Schedule (WHO/DAS) [Internet]. Geneva (Switzerland): World Health Organization; 2000 [cited 2011 Dec 16]. Available from: http://www.who.int/icidh/whodas/whodasversions/ 36intdc.pdf

51. McHorney CA, Ware JE Jr, Raczek AE. The MOS 36-Item Short-Form Health Survey (SF-36): II. Psychometric and clinical tests of validity in measuring physical and mental health constructs. Med Care. 1993;31(3):247-63.

[PMID:8450681] http://dx.doi.org/10.1097/00005650-199303000-00006

52. Stewart AL, Ware JE. Measuring functioning and wellbeing: the medical outcome study approach. Durham (NC): Duke University Press; 1992.

53. Sheehan DV. The anxiety disease. New York (NY): Scribner; 1983.

54. World Health Organization. World Health Organization Health and Performance Questionnaire (HPQ): Clinical trials baseline version. Geneva (Switzerland): World Health Organization; 2002.

55. Lerner D, Amick BC 3rd, Rogers WH, Malspeis S, Bungay K, Cynn D. The Work Limitations Questionnaire. Med Care. 2001;39(1):72-85. [PMID:11176545] http://dx.doi.org/10.1097/00005650-200101000-00009

56. Adler DA, Possemato K, Mavandadi S, Lerner D, Chang H, Klaus J, Tew JD, Barrett D, Ingram E, Oslin DW. Psychiatric status and work performance of veterans of Operations Enduring Freedom and Iraqi Freedom. Psychiatr Serv. 2011;62(1):39-46. [PMID:21209298] http://dx.doi.org/10.1176/appi.ps.62.1.39

57. Reilly MC, Zbrozek AS, Dukes EM. The validity and reproducibility of a work productivity and activity impair- 
ment instrument. Pharmacoeconomics. 1993;4(5):353-65. [PMID:10146874]

http://dx.doi.org/10.2165/00019053-199304050-00006

58. Weissman MM, Bothwell S. Assessment of social adjustment by patient self-report. Arch Gen Psychiatry. 1976; 33(9):1111-15. [PMID:962494] http://dx.doi.org/10.1001/archpsyc.1976.01770090101010

59. Spanier GB. Measuring dyadic adjustment: New scales for assessing the quality of marriage and similar dyads. J Marriage Fam. 1976;38(1):15-28.

http://dx.doi.org/10.2307/350547

60. Moos RH, Moos BS. The life stressors and social resources inventory-Adult form: Professional manual. Odessa (FL): Psychological Assessment Resources; 1994.

61. Schneier FR, Heckelman LR, Garfinkel R, Campeas R, Fallon BA, Gitow A, Street L, Del Bene D, Liebowitz MR. Functional impairment in social phobia. J Clin Psychiatry. 1994;55(8):322-31. [PMID:8071299]

62. Tyrer P, Nur U, Crawford M, Karlsen S, McLean C, Rao B, Johnson T. The Social Functioning Questionnaire: a rapid and robust measure of perceived functioning. Int J Soc Psychiatry. 2005;51(3):265-75. [PMID:16252794] http://dx.doi.org/10.1177/0020764005057391

63. Goldstein MJ. Further data concerning the relation between premorbid adjustment and paranoid symptomatology. Schizophr Bull. 1978;4(2):236-43. [PMID:746374]

64. Endicott J, Nee J, Harrison W, Blumenthal R. Quality of life enjoyment and satisfaction questionnaire: A new measure. Psychopharmacol Bull. 1993;29(2):321-26. [PMID:8290681]

65. Blake DD, Weathers FW, Nagy LM, Kaloupek DG, Gusman FD, Charney DS, Keane TM. The development of a Clinician-Administered PTSD Scale. J Trauma Stress. 1995;8(1):75-90. [PMID:7712061] http://dx.doi.org/10.1002/jts.2490080106

66. First MB, Spitzer RL, Gibbon M, Williams JB. User's guide for the Structured Clinical Interview for DSM-IV-TR Axis I Disorders, Clinician Version (SCID-I) biometrics research. New York (NY): New York State Psychiatric Institute; 1997.

67. Himle JA, Baser RE, Taylor RJ, Campbell RD, Jackson JS. Anxiety disorders among African Americans, blacks of Caribbean descent, and non-Hispanic whites in the United States. J Anxiety Disord. 2009;23(5):578-90.

[PMID: 19231131] http://dx.doi.org/10.1016/j.janxdis.2009.01.002

68. Rasmussen A, Nguyen L, Wilkinson J, Vundla S, Raghavan S, Miller KE, Keller AS. Rates and impact of trauma and current stressors among Darfuri refugees in Eastern Chad. Am J Orthopsychiatry. 2010;80(2):227-36.

[PMID:20553516] http://dx.doi.org/10.1111/j.1939-0025.2010.01026.x
69. Sayer NA, Spoont M, Nelson DB, Clothier B, Murdoch M. Changes in psychiatric status and service use associated with continued compensation seeking after claim determinations for posttraumatic stress disorder. J Trauma Stress. 2008;21(1):40-48. [PMID: 18302170]

http://dx.doi.org/10.1002/jts.20309

70. Spoont MR, Sayer NA, Nelson DB, Nugent S. Does filing a post-traumatic stress disorder disability claim promote mental health care participation among veterans? Mil Med. 2007;172(6):572-75. [PMID:17615834]

71. Spoont M, Sayer N, Nelson D, Clothier B, Murdoch M, Nugent S. Does clinical status change in anticipation of a PTSD disability examination? Psychol Serv. 2008;5(1):49-59. http://dx.doi.org/10.1037/1541-1559.5.1.49

72. World Health Organization. International classification of functioning, disability and health: ICF. Geneva (Switzerland): WHO; 2000.

73. Keller MB, Lavori PW, Friedman B, Nielsen E, Endicott J, McDonald-Scott P, Andreasen NC. The Longitudinal Interval Follow-up Evaluation. A comprehensive method for assessing outcome in prospective longitudinal studies. Arch Gen Psychiatry. 1987;44(6):540-48.

[PMID:3579500]

http://dx.doi.org/10.1001/archpsyc.1987.01800180050009

74. McDevitt-Murphy ME, Parra GR, Shea MT, Yen S, Grilo CM, Sanislow CA, McGlashan TH, Gunderson JG, Skodol AE, Markowitz JC. Trajectories of PTSD and substance use disorders in a longitudinal study of personality disorders. Psychol Trauma. 2009;1(4):269-81. http://dx.doi.org/10.1037/a0017831

75. Ouimette P, Wade M, Coolhart D, Tirone V, Goodwin E, Semenec S. Measuring PTSD course among substance use disorder patients: A pilot study of the interrater reliability and validity of the Longitudinal Interval Follow-up Evaluation (LIFE). Traumatology. 2010;16(3):19-26. http://dx.doi.org/10.1177/1534765610368570

76. Guyatt G, Walter S, Norman GJ. Measuring change over time: assessing the usefulness of evaluative instruments. J Chronic Dis. 1987;40(2):171-78. [PMID:3818871] http://dx.doi.org/10.1016/0021-9681(87)90069-5

77. Cicchetti D. Guidelines, criteria, and rules of thumb for evaluating normed and standardized assessment instruments in psychology. Psychol Assess. 1994;6(4):284-90. http://dx.doi.org/10.1037/1040-3590.6.4.284

78. American Psychiatric Association. Diagnostic and statistical manual of mental disorders, 4th edition. Washington (DC): American Psychiatric Association; 2000. p. 943.

79. Young G, Johnson R. Posttraumatic stress disorder in the DSM-5: Group difference commentary. Psychol Inj Law. 2010;3(4):314-19. http://dx.doi.org/10.1007/s12207-010-9093-9 
80. American Psychiatric Association, Task For the DSM-5 Development. G 03 posttraumatic stress disorder [Internet]. Arlington (VA): American Psychiatric Association; 2012 [updated 2012 May 1; cited 2011 Nov 29]. Available from: http://www.dsm5.org/ProposedRevision/Pages/proposedrevision.aspx?rid=165

81. Wright KM, Cabrera OA, Eckford RD, Adler AB, Bliese PD. The impact of predeployment functional impairment on mental health after combat. Psychol Trauma. 2011. http://dx.doi.org/10.1037/a0024373

82. Cukor J, Wyka K, Jayasinghe N, Difede J. The nature and course of subthreshold PTSD. J Anxiety Disord. 2010; 24(8):918-23. [PMID:20655169] http://dx.doi.org/10.1016/j.janxdis.2010.06.017

83. Stein MB, Walker JR, Hazen AL, Forde DR. Full and partial posttraumatic stress disorder: findings from a community survey. Am J Psychiatry. 1997;154(8):1114-19. [PMID:9247398]

84. Zlotnick C, Franklin CL, Zimmerman M. Does “subthreshold” posttraumatic stress disorder have any clinical relevance? Compr Psychiatry. 2002;43(6):413-19. [PMID:12439826] http://dx.doi.org/10.1053/comp.2002.35900

85. Ustün B, Kennedy C. What is “functional impairment”? Disentangling disability from clinical significance. World Psychiatry. 2009;8(2):82-85. [PMID:19516924]

86. Holowka D, Marx BP. Assessing functioning and quality of life after trauma exposure. In: Beck JG, Sloan DM, editors. The Oxford handbook of traumatic stress disorders. New York (NY): Oxford University Press; 2012.

87. Institute of Medicine. PTSD compensation and military service. Washington (DC): National Academies Press; 2007.

88. Goldman HH. 'Do you walk to school, or do you carry your lunch?’ Psychiatr Serv. 2005;56(4):419. http://dx.doi.org/10.1176/appi.ps.56.4.419

89. Nunnally JC. Psychometric theory, 2nd ed. New York (NY): McGraw-Hill; 1978.

90. Frueh BC, Smith DW, Barker SE. Compensation seeking status and psychometric assessment of combat veterans seeking treatment for PTSD. J Trauma Stress. 1996;9(3): 427-39. [PMID:8827647] http://dx.doi.org/10.1002/jts.2490090303

91. Gold PB, Frueh BC. Compensation-seeking and extreme exaggeration of psychopathology among combat veterans evaluated for posttraumatic stress disorder. J Nerv Ment Dis. 1999;187(11):680-84. [PMID:10579596] http://dx.doi.org/10.1097/00005053-199911000-00005
92. Butcher JN, Dahlstrom WC, Graham JR, Tellegen A, Kaemmer B. MMPI-2: Minnesota Multiphasic Personality Inventory-2. Manual for administration and scoring. Minneapolis (MN): University of Minnesota Press; 1989.

93. Widows MR, Smith GP. SIMS: Structured inventory of malingered symptomatology, professional manual. Lutz (FL): Psychological Assessment Resources; 2005.

94. Miller HA. MFAST: Miller Forensic Assessment of Symptoms Test professional manual. Odessa (FL): Psychological Assessment Resources; 2001.

95. Hyer L, Boudewyns P, Harrison WR, O’Leary WC, Bruno RD, Saucer RT, Blount JB. Vietnam veterans: overreporting versus acceptable reporting of symptoms. J Pers Assess. 1988;52(3):475-86. [PMID:3210120] http://dx.doi.org/10.1207/s15327752jpa5203 9

96. Franklin CL, Repasky SA, Thompson KE, Shelton SA, Uddo M. Differentiating overreporting and extreme distress: MMPI-2 use with compensation-seeking veterans with PTSD. J Pers Assess. 2002;79(2):274-85.

[PMID:12425391]

http://dx.doi.org/10.1207/S15327752JPA7902 10

97. Freeman T, Powell M, Kimbrell T. Measuring symptom exaggeration in veterans with chronic posttraumatic stress disorder. Psychiatry Res. 2008;158(3):374-80.

[PMID:18294699]

http://dx.doi.org/10.1016/j.psychres.2007.04.002

98. DeViva JC, Bloem WD. Symptom exaggeration and compensation seeking among combat veterans with posttraumatic stress disorder. J Trauma Stress. 2003;16(5):503-7.

[PMID:14584635]

http://dx.doi.org/10.1023/A:1025766713188

99. American Psychiatric Association. Diagnostic and statistical manual of mental disorders, 3rd edition. Washington (DC): American Psychiatric Association; 1980.

Submitted for publication September 6, 2011. Accepted in revised form January 9, 2012.

This article and any supplementary material should be cited as follows:

Rodriguez P, Holowka DW, Marx BP. Assessment of posttraumatic stress disorder-related functional impairment: A review. J Rehabil Res Dev. 2012;49(5):649-66. http://dx.doi.org/10.1682/JRRD.2011.09.0162

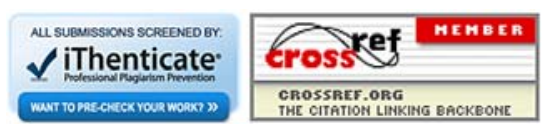


